
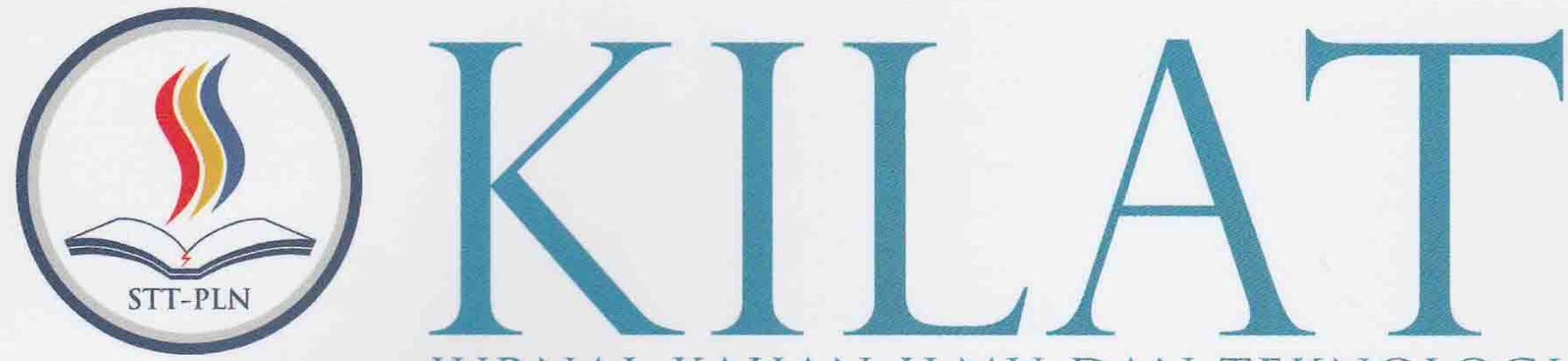

JURNAL KAJIAN ILMU DAN TEKNOLOGI

Endah Lestari: Irma Wirantina K: Ranti Hidayawanti

Faisal:

Muhammad Ridwan: Mardawati

Gita Puspa Artiani: Indah Handayasari

Kresna Ramanda; Irmawati Carolina

Ratna Mutu Manikam:

Farid Setiawan

Rayung Wulan

Roni Kartika Pramuyanti

Rr. Mekar Ageng Kinasti; Djoko Nugroho Notodisuryo

Satria;

Ayu Setiawati Agustini

Syam Gunawan: Pritasari Palupiningsih

Ali Ridho Gumelar: Anton: Ummu Radiyah

M. Yoga Distra Sudirman: Yessy Fitriani
ANALISA TAMAN ATAP DALAM UPAYA MENGURANGI LIMPASAN AIR HUJAN PADA BANGUNAN PERKOTAAN

OPTIMASI DIAGRAM LAYANAN PEMBELIAN DALAM MENDUKUNG MANAJEMEN HUBUNGAN PELANGGAN

OPTIMALISASI PENGOLAHAN SAMPAH ORGANIK DENGAN TEKNOLOGI BIODIGESTER SEBAGAI UPAYA KONSERVASI LINGKUNGAN

SELEKSI FITUR ALGORITMA NEURAL NETWORK MENGGUNAKAN PARTICLE SWARM OPTIMIZATION UNTUK MEMPREDIKSI KELAHIRAN PREMATUR

RANCANG BANGUN MEDIA BELAJAR FISIKA DASAR UNTUK MAHASISWA BERBASIS ANDROID

ANALISIS GLOBAL POSITIONING INFRASTRUKTUR DAN JARINGAN SOSIAL MEDIA DALAM BISNIS APLIKASI TRANSPORTASI DARAT ONLINE DI JAKARTA

PENGARUH INOVASI ANTENA PADA SIARAN TELEVISI MOBIL

PEMANFAATAN LIMBAH PEMBAKARAN BATUBARA (BOTTOM ASH) PADA PLTU SURALAYA SEBAGAI MEDIA TANAM DALAM UPAYA MENGURANGI PENCEMARAN LINGKUNGAN

PENERAPAN METODE GRAPHIC RATING SCALE (GRS) DALAM PENILAIAN KINERJA KARYAWAN

PEMBENTUKAN MODEL KLASIFIKASI DATA LAMA STUDI MAHASISWA STMIK INDONESIA MENGGUNAKAN DECISION TREE DENGAN ALGORITMA NBTREE

IMPLEMENTASI LOAD BALANCING DENGAN ALGORITMA EQUAL COST MULTI PATH (ECMP)

RANCANGAN SISTEM PENILAIAN HASIL KINERJA MULTI COMPANY DAN CROSS BUSINESS SECTOR 


\title{
IMPLEMENTASI LOAD BALANCING DENGAN ALGORITMA EQUAL COST MULTI PATH (ECMP)
}

\author{
Ali Ridho Gumelar; Anton; Ummu Radiyah \\ Program Studi Teknik Informatika \\ Sekolah Tinggi Manajemen Informatika dan Komputer Nusa Mandiri Jakarta
}

\begin{abstract}
ABSTRAK
Perkembangan pesat internet membutuhkan penyeimbang dalam menjaga konektifitas dan stabilitas jaringan. konektifitas menjadi salah satu aspek yang menjadi prioritas dalam sebuah jaringan, maka dari itu koneksi internet di tuntut untuk selalu stabil dan bebas gangguan, tapi tidak selamanya sebuah koneksi berjalan dengan lancar dan stabil. Biasanya terdapat berbagai macam gangguan dalam sebuah jaringan, maka diperlukannya manajemen bakcup dari jaringan yang sedang berjalan sehingga jika salah satu mengalami gangguan maka akan ada backup. Salah satu yang bisa dilakukan adalah dengan menggunakan metode load balancing. Subyek yang diambil dalam penelitian ini fokus terhadap penerapan backup dari sumber jaringan Internet atau backup dari ketergantungan satu provider jasa penyedia internet atau ISP. Untuk metode load balancing yang digunakan yaitu menggunakan metode Equal Cost Multi Path, metode penelitian yang dilakukan dilakukan yaitu studi pustaka, observasi dan wawancara terhadap jaringan PT.Nipindo. Sedangkan untuk perancangan dimulai dengan menginstal mikrotik yang selanjutnya dapat diterpakan load balancing. Uji teknis dilakukan dengan menggunakan tes ping ini dilakukan untuk mengetahui apakah koneksi berjalan dengan baik ataupun tidak. Hasil dari penerapan load balancing dengan metode ECMP ini menunjukan load balancing berjalan dengan baik. Load balancing tidak mengubah struktur fisik dari sebuah jaringan yang telah ada, sehingga bisa dihasilkan koneksi yang optimal ketika terjadi kenaikan lalu lintas karena pembagian bandwidth yang seimbang.
\end{abstract}

Kata Kunci: Load Balancing, Backup ,ISP, Mikrotik, Bandwidth.

\begin{abstract}
The rapid development of the Internet requires a counterweight in maintaining connectivity and network stability. connectivity becomes one of the aspects that take priority in a network, and therefore the Internet connection on demand to always be stable and interference free, but not always a connection running smoothly and stable. Usually there are a variety of disorders within a network, hence the need for bakcup management of the network that are running so that if one impaired then there will be a backup. One that can be done is by using load balancing. Subyek taken in this study to focus on the implementation of the source network backup or backup Internet from the dependence of the internet service provider or ISP provider. Load balancing method using Equal Cost Multi-Path, research methods that used are library research, observation and interviews network of PT.Nipindo. As for the design begins with installing mikrotik here in after may be applied load balancing. Technical test carried out by using a ping test is performed to determine whether the connection is running well or not. The result of applying load balancing method shows ECMP load balancing goes well. Load balancing does not change the physical structure of an existing network, so it can produce optimal connections when an increase in traffic due to the balanced distribution of bandwidth.
\end{abstract}

Keywords: Load Balancing, Backup, ISP, Mikrotik, Bandwidth.

\section{PENDAHULUAN}

\subsection{Latar Belakang Masalah}

Pada perkembangan era teknologi saat ini kebutuhan akan efektifitas waktu sangat diperlukan tidak hanya dalam masalah sehari-hari saja tetapi juga dalam masalah jaringan komputer, maka dari itu di dalam dunia jaringan komputer dikenal istilah manajemen bandwidth. Manajemen bandwidth merupakan sebuah metode atau alat untuk mengontrol dan mengoptimalisasi lalu lintas jaringan dengan cara menetapkan tipe-tipe lalulintas jaringan, sehingga mampu meningkatkan kualitas servis dari jaringan itu sendiri. Masalah yang umum terjadi dalam sebuah lalu-lintas adalah traffic yang mana bisa mempengaruhi lama cepatnya sebuah perjalanan dalam hal ini adalah lalu-lintas paket data sehingga perlu adanya manajemen agar bisa mengatur dan mengontrol agar tidak terjadi traffic selain itu juga perlu adanya optimalisasi sehingga ketika adanya luapan data bisa ditangani dengan baik. Masalah ini umumnya juga terjadi pada perusahaan, instansi, maupun organisasi yang mana membutuhkan mobilitas tinggi dalam penyaluran data dan PT.Nipindo Primatama salah satunya.

PT.Nipindo Primatama merupakan perusahaan yang bergerak pada bidang industri jasa pertambangan, kontraktor sipil, kontraktor mekanikal-elektrikal dan developer (property). Masalah yang ada saat ini pada PT.Nipindo Primatama adalah tidak adanya backup jaringan yang bisa menunjang ketika ada gangguan pengiriman paket data, sehingga jalur paket data 
yang sedang berjalan sangat mungkin terjadi gangguan dan dapat mengganggu produktivitas para staff, selain itu manajemen bandwidth kurang efektif dalam penggunaannya.

Sebuah jaringan yang besar cenderung akan melambat akibat lalu lintas data yang terlalu padat sehingga terjadi apa yang dinamakan congestion atau kemacetan. Membagi sebuah jaringan yang besar menjadi jaringan-jaringan yang lebih kecil dinamakan network segmentation yang bisa dilakukan dengan menggunakan router, switch dan bridge (Ramandito,dkk,2010).

\subsection{Tujuan Penelitian}

Adapun tujuan penelitian ini adalah:

1. Memberikan kualitas layanan yang handal

2. Menerapkan metode load balancing equal cost multi path.

3. Memiliki kemampuan untuk beradaptasi dengan berbagai permasalahan yang memungkinkan terputusnya koneksi jaringan.

4. Menerapkan penggunaan dua ISP dalam jaringan

\section{METODE PENELITIAN}

\subsection{Metode penelitian}

Metode penelitian yang digunakan adalah eksperimen menggunakan aplikasi simulator. Pada penelitian ini dilakukan percobaan dan implementasi mengenai kinerja dari metode load balancing. Hasil eksperimen selanjutnya di dokumentasikan untuk melakukan analisa sehingga dihasilkan rekomendasi yang tepat untuk pemecahan masalah yang ada. Dari hasil analisa tersebut nantinya akan mendapatkan kesimpulan mengenai manfaat serta fungsi yang lebih detail lagi.

\section{A. Analisa Kebutuhan}

Analisa kebutuhan untuk implementasi berupa perangkat keras dan perangkat lunak, untuk perangkat keras minimal meliputi :

a. Personal computer (PC) maupun laptop prosesor intel pentium IIII atau yang setara, memory $1 \mathrm{~GB}$, dan harddisk $120 \mathrm{~GB}$.

b. Kabel UTP straight dan crossover

c. Router Board Mikrotik

d. Crimping tool

Adapun kebutuhan minimal untuk perangkat lunak meliputi:

a. Mikrotik Operating System

b. Winbox

Selain itu kebutuhan perancangan melalui simulator membutuhkan PC atau laptop yang support aplikasi seperti GNS3, packet tracer, Boson dan sejenisnya.

\section{B. Desain}

Untuk desain penulis menggunakan simulator GNS3 yang di dalamnya terdapat fitur yang dapat mendeskripsikan kebutuhan desain untuk metode yang penulis gunakan yaitu meliputi topologi, analisis kebutuhan IP dan rancang skema dari metode yang digunakan.

\section{Testing}

Untuk pengujian metode load balancing yang digunakan yaitu dengan memberikan tes ping, dengan melakukan tes ping maka dapat dilihat ketika ada dua jalur dan salah satu jalur down.

\section{Implementasi}

Implementasi metode load balancing untuk realnya diharapkan akan akan dilaksanakan pada PT.Nipindo Primatama Jakarta, karena ditinjau dari kebutuhan dan efektifitas manajemen memang dibutuhkan perusahaan, sedangkan untuk perancangan dan konfigurasi sebelum di implementasikan maka digunakan simulator yang memang relevan dengan keadaan di lapangan, sehingga ketika akan dilakasanakan implementasi langsung tidak ada perbedaan yang signifikan.

\subsection{Metode Pengumpulan Data}

1. Observasi

Penulis melakukan observasi penelitian pada PT. Nipindo di ruang pusat data dalam mengumpulkan informasi serta di bimbing oleh salah satu staff IT support.

\section{Wawancara}

Penulis melakukan wawancara dalam mengumpulkan data yang di butuhkan kepada salah satu staff IT support yang bernama bapak Abdul Holik di waktu senggang jam kerja.

3. Studi pustaka

Penulis membaca dan mempelajari referensi dari buku atau artikel ilmiah yang berkaitan dengan manajemen bandwidth untuk mengumpulkan informasi terkait.

\section{HASIL DAN PEMBAHASAN}

Load balance dalam jaringan komputer adalah teknik untuk membagi beban (load) ke dalam beberapa jalur atau link. Hal ini dilakukan jika untuk menuju suatu network terdapat beberapa jalur (link)[5]. Tujuan dari load balance ini agar tidak ada link yang mendapat beban lebih besar dari link yang lain. Diharapkan dengan membagi beban ke dalam beberapa link tersebut, maka akan tercapai keseimbangan (balance) penggunaan link-link tersebut. Ada berbagai macam implementasi load balance yang sering dijumpai di lapangan, yang paling sering adalah penerapan load balance pada suatu jaringan lokal yang memiliki dua atau lebih koneksi ke internet. Koneksi-koneksi tersebut bisa berasal dari ISP yang sama maupun berasal dari ISP yang berbeda (Todjowojoyo,2016)

ECMP dikenal sebagai teknik load balancing yang paling sederhana dan lebih cocok digunakan pada jaringan dengan tingkat kompleksitas yang tidak terlalu tinggi. Pembagian beban dalam metode ini menggunakan pengaturan perbandingan langsung antara beban yang diterima oleh setiap gateway. Tujuan penerapan algoritma ini yaitu untuk dimungkinkan adanya penggunaan lebih dari satu jalur gateway digunakan sebagai exit interface dan mendapatkan pembagian beban yang merata antar tiap gateway dalam membagi traffic yang ada. Dalam penggunaannya algoritma ini juga 
mendukung penggunaan routing static maupun dynamic (Ramandito, dkk,2016).

Dalam perancangan aplikasi penerapan metode load balancing ada beberapa tahap yang harus dilalui atau dijalankan diantaranya dengan melakukan setting pada NAT, DNS, DHCP Client, Mangle, dan Routing. Proses Setting dari rancangan aplikasi sebagai berikut:

a. Routing

Langkah untuk melakukan metode load balancing ini yaitu harus dilakukan routing terlebih dahulu,dimana routing merupakan teknik yang digunakan untuk menghubungkan beberapa jaringan yang memiliki network address maupun teknologi yang berbeda-beda. Routing juga bertujuan memilihkan jalur yang terbaik yang akan di tempuh paket data untuk menuju komputer tujuan.

Sedangkan untuk konfigurasi secara console adalah sebagai berikut:

/ip route

Add dst-address $=0.0 .0 .0 / 0$

gateway=192.168.56.101 routing-

mark $=k e \_I S P 1$

Add dst-address $=0.0 .0 .0 / 0$

gateway=192.168.56.101 routing-

mark=ke_ISP2

b. NAT ( Network Address Translation)

Untuk tahap selanjutnya settingan NAT yang merupakan fitur pada firewall yang digunakan untuk melakukan perubahan field IP address, baik IP address pengirim maupun IP address tujuan. NAT juga dapat melakukan perubahan field port pengiriman maupun port tujuan pada paket data. adalah:

Konfigurasi yang digunakan untuk NAT

/ip firewall

Ip firewall nat add chain=srcnat outinterface $=I S P 1$ action=masquerade Ip firewall nat add chain=srcnat outinterface $=I S P 2$ action=masquerade

\section{c. DHCP Client}

Sebenarnya untuk pemberian IP address bisa saja menggunakan konfigurasi secara manual untuk pelaksanaannya, tetapi membutukan waktu yang lama untuk melakukan pengaturannya, maka dari itu untuk mengefesiensi waktu digunakanlah DHCP Client karena akan diberikan pool IP yang nantinya tiap pool IP memberikan IP secara otomatis ke client ataupun pengguna.

Konfigurasi untuk DHCP Client dapat dilihat di bawah ini:

/ip dhcp-client

add add-default-route=yes default-routedistance $=0$ disabled $=$ no interface $=1$ Lokal use-peer-dns=yes use-peer-ntp=yes add add-default-route=yes default-routedistance $=0$ disabled $=$ no interface $=I S P 2$ use-peer-dns=yes use-peer-ntp=yes add add-default-route=yes default-routedistance $=0$ disabled $=$ no interface $=\mid S P 1$ use-peer-dns=yes use-peer-ntp=yes

d. DNS (Domain Name System)
Merupakan sebuah sistem yang menyimpan informasi tentang nama host ataupun nama domain, selain itu DNS merupakan layanan jaringan yang menerjemahkan situs web menjadi alamat inernet. Maka dari itu DNS menjadi peran yang penting ketika akan mengunjungi sebuah situs ataupun web.

lip dns

Ip dns set servers $=8.8 .8 .8$ allow-remoterequest=yes

Maksud dari allow remote request di atas adalah untuk menjadikan router mikrotik yang aktif sebagai DNS server, sehingga dapat menghemat penggunaan bandwidth dikrenakan pertanyaan DNS hanya akan diberikan ke router mikrotik.

\section{e. Mangle}

Settingan mangle adalah tahapan berikutnya digunakan untuk menandai paket atau marking, untuk tanda yang diberikan kepada paket data, hanya dibaca dan digunakan pada router yang bersangkutan. Marking tersebut akan dilepas pada saat paket akan meninggalkan router. Sehingga marking pada suatu router tidak dapat digunakan pada router lain.

Sedangkan untuk konfigurasinya dapat di jabarkan sebagai berikut:

lip firewall mangle

add chain=input in-interface=ether $1-I S P 1$

action=mark-connection new-connection-

mark=ISP1_conn

add chain=input in-interface $=$ ether1-ISP2

action $=$ mark-connection new-connectionmark=ISP2 conn

add chain=output in-interface $=I S P 1$ conn

action=mark-connection new-routing-

mark=ke ISP1

add chain=output in-interface $=I S P 2$ conn

action=mark-connection new-routing-

mark=ke_ISP2

\subsection{Manajemen Jaringan}

Untuk manajemen jaringan dalam implementasi metode load balancing ini dapat di artikan sebagai kemampuan untuk mengontrol dan memonitoring sebuah jaringan pada lokasi tertentu, dalam hal ini aspek seperti keamanan, kesalahan, informasi dan konfigurasi menjadi vital dikarenakan aspek-aspek yang disebutkan tadi merupakan komponen utama untuk terbentuknya sebuah jaringan yang baik. Adapun untuk load balancing aspek-aspek tersebut dapat dijabarkan sebagai berikut:

1. Aspek Manajemen Kesalahan

Pada load balancing menggunakan mikrotik yang penulis bahas untuk aspek ini digunakan atau berfungsi sebagai fasilitas yang memungkinkan administrator mengetahui kesalahan perangkat yang dikelola.

Dalam load balancing penulis menggunakan tools winbox sebagai cara untuk meminimalisasi kesalahan, Ini dikarenakan winbox berbasis GUI (Graphical User Interface).

2. Aspek Manajemen Konfigurasi

Manajemen konfigurasi merupakan cara agar jaringan berjalan secara optimal baik itu 
perangkat keras maupun perangkat lunak dapat dikelola dengan baik, dalam load balancing cara untuk mengoptimalkan sumber daya dalam hal ini dua ISP maka digunakan konfigurasi failover, yang merupakan sebuah cara untuk mengalihkan jalur koneksi secara otomatis jika ada salah satu ISP yang down. Berikut adalah konfigurasi untuk failover: Ip route add dst-address $=192.168 .2 .0 / 24$ gateway=10.1.1.1.2 check-gateway=ping Ip route add dst-address $=192.168 .2 .0 / 24$ gateway=10.10.10.2 distance $=2$ checkgateway=ping

3. Aspek Manajemen Informasi

Aspek ini bertujuan untuk menghasilkan informasi dalam menjaga performa jaringan selain itu dapat juga untuk mengukur aspek dari performa jaringan termasuk pengumpulan dan analisis data sehingga dapat dikelola dan dipertahankan pada level tertentu. Di bawah ini merupakan fitur manajemen informasi dan monitoring yang terdapat pada winbox.

Terlihat di atas bahwa apabila menggunakan aplikasi winbox akan lebih mudah untuk mendapatkan informasi dari jaringan yang berjalan dibandingkan secara analog atau pada mikrotik langsung.

4. Aspek Manajemen Keamanan

Aspek ini menjadi aspek yang penting karena mengatur akses menuju sumber daya jaringan sehingga informasi tidak dapat diperoleh tanpa izin. Untuk meminimalisasi hal itu maka perlu dilakukan pemberian password untuk membatasi hak akses sehingga tidak sembarangan orang bisa mengakses jaringan yang sedang berjalan, hanya orang yang mempunyai otorisasi saja yang bisa masuk.

Dengan pemberian password maka dapat meminimalisasi orang yang tidak bertanggung jawab bisa masuk ke dalam jaringan, sehingga sumber daya yang ada tidak bisa disalahgunakan.

\subsection{Pengujian Jaringan}

Pengujian jaringan yang penulis lakukan adalah dengan menggunakan tes ping. Dimana ketika tes ping dilakukan akan terlihat apakah load balancing yang diterapkan sudah berjalan dengan baik ataupun masih ada masalah yang harus diperbaiki.

Pengujian awal dilakukan untuk mengetahui bahwa ketika sebelum load balancing diimplementasikan kedua ISP tidak saling membackup.

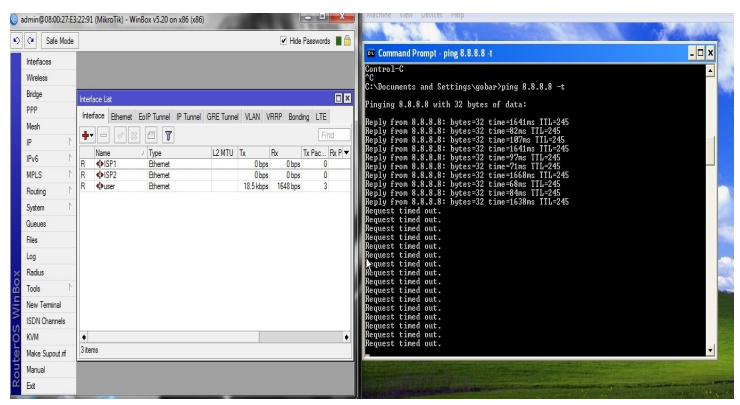

Sumber: Pribadi

Gambar 3.1 Jaringan Awal
Dari gambar di atas dapat diamati bahwa sebelum adanya load balancing walaupun ada dua ISP yang aktif tetapi masih adanya request timed out, ini menandakan belum adanya pembagian jalur sehingga yang terbaca hanya satu jalur saja, dan tentu saja untuk hasil pengamatan di atas penerapan load balancing memang diperlukan sehingga mampu membagi rata beban antara ISP pertama dan ISP kedua dan dapat mengoptimalkan sumber daya ISP yang tersedia.

Dalam pengujian jaringan akhir dijabarkan bagaimana pengujian jaringan dilakukan ketika dicoba dengan tes koneksi dan juga ditampilkan bagaimana efek pada jaringan setelah dilakukannya load balancing. Pada dasarnya teknik ECMP ini adalah dengan mengkonfigurasi dua gateway antara network satu dan network lainnya sehingga kedua network bisa terhubung dan membagi beban secara merata. Selain membagi beban secara merata alasan kenapa mengambil load balancing dengan metode equal cost multi path ialah bisa membagi beban jaringan berdasarkan perbandingan kecepatan antara dua ISP jadi tidak hanya sekedar membagi tetapi juga bisa memilih ISP mana yang dijadikan prioritas hal ini didasarkan pada kecepatan masing-masing ISP sehingga bisa memaksimalkan sumber daya yang ada. Untuk selanjutnya ketika teknik ini diimplementasikan dapat diketahui apakah berjalan dengan baik dan lancar ataukah terdapat kendala yang menghambat implementasi load balancing ini. Di bawah ini adalah gambar IV.11 dari pengujian jaringan akhir dimana ISP pertama disimulasikan mengalami putus koneksi.

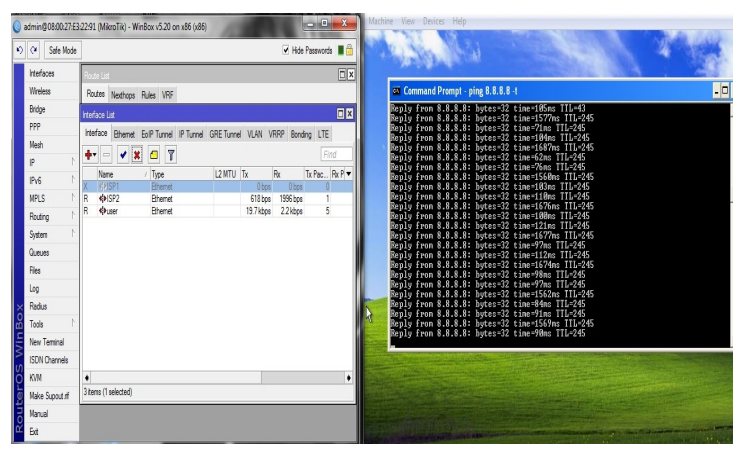

Sumber: Pribadi

Gambar 3.2 ISP 1 Down

Gambar di atas diambil ketika kondisi ISP satu dimatikan atau dalam realnya mengalami down, terlihat bahwa koneksi masih berjalan dengan baik.

Untuk selanjutnya disimulasikan apabila jalur ISP dua yang dimatikan atau mengalami down. 


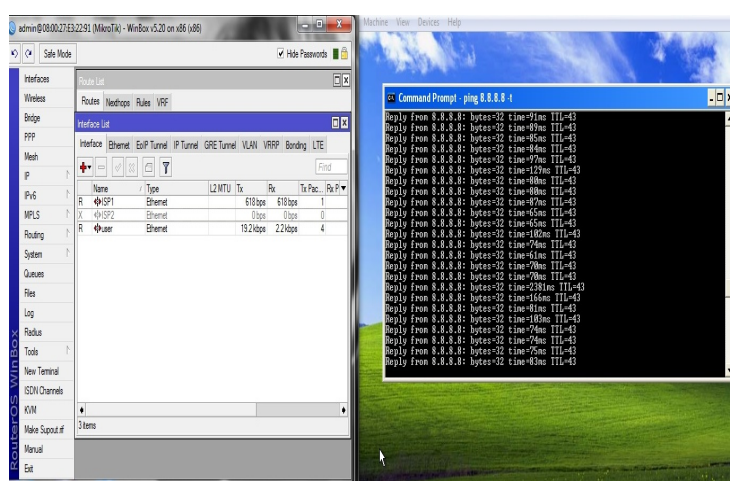

Sumber : Pribadi

Gambar 3.3 ISP 2 down

Terlihat bahwa koneksi masih berjalan dengan baik ketika ISP dua dimatikan atau down, ini berarti load balancing sudah berjalan dengan baik. Dan dapat dibuktikan dari hasi tes ping dengan adanya reply from ini menandakan koneksi tidak terjadi gangguan ataupun masalah.

Sekarang bagaimana apabila kedua ISP mengalami down atau terputus, di bawah ini adalah hasil dari tes ping yang dilakukan apabila kedua ISP terputus.

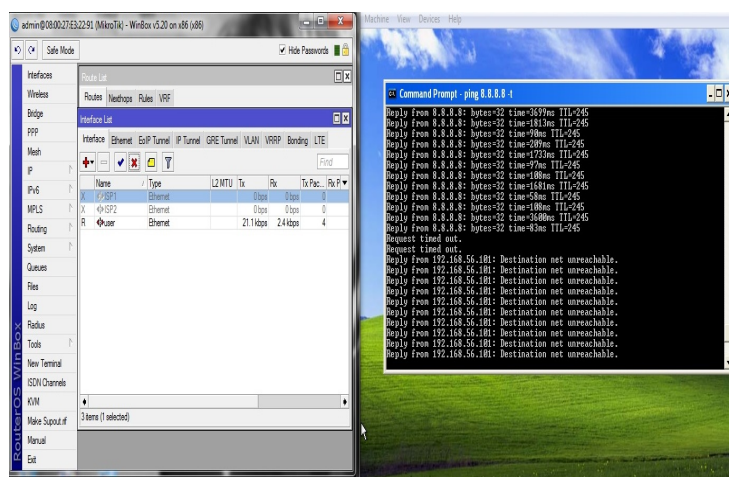

Sumber : Pribadi

Gambar 3.4 Kedua ISP down

Dapat diliahat bahwa ketika kedua ISP mengalami down atau terputus secara otomatis koneksi juga terputus, ini dibuktikan dengan adanya pesan destination host unreacheble.

\section{KESIMPULAN DAN SARAN}

\subsection{Kesimpulan}

1. Metode ECMP (Equal Cost Multi Path) terbukti dari pengujian yang telah dilakukan mampu membagi beban ketika ada salah satu link atau jalur mengalami putus koneksi, sehingga mampu membeikan kualitas layanan yang handal.

2. Teknik failover dapat menjadikan salah satu gateway menjadi koneksi tunggal ketika koneksi atau jalur yang lain mengalami down.

\subsection{Saran}

1. Untuk penerapan load balancing ini diutamakan jalur prioritas mempunyai bandwidth yang lebih cepat, sehingga dapat mengoptimalkan sumber daya yang ada.

2. Mengoptimalkan fitur manajemen bandwidth yang ada dalam mikrotik agar dapat membagi rata bandwidth sesuai dengan jumlah user atau pengguna yang aktif.

3. Dalam pemeilihan ISP sebaiknya memilih ISP dengan kualitas ataupun kecepatan koneksi yang hampir sama, ini bertujuan agar stabilitas jaringan terjaga dengan baik.

\section{DAFTAR PUSTAKA}

Graphical Network Simulator. DocumentationGNS3. Diambil dari: http//www.gns3.com/support/docs. November 2016).

Haryanto, dedy M dan Riadi I (2014). Analisis dan Optimalisasi Jaringan Menggunakan Teknik Load Balancing. ISSN: 2338-5197. Yogyakarta: Jurnal Sarjana Teknik Informatika Vol. 2 No. 2 Juni 2014. Diambil dari: http://journal.uad.ac.id/index.php/JSTIF/article/ view/2887

Mikrotik Indonesia. Load Balance Metode ECMP. Diambil dari: http//mikrotik.co.id/artikel_lihat.php?id=76. $(20$ November 2016).

Ramandito, Sumaryono R.S, dan Kusumawardhani S.S, (2010). Analisis Performance Jaringan Komputer Dengan Mekanisme Load Balancing-Failover. Yogyakarta: Jurnal Penelitian Teknik Elektro Vol.3 No. 4 Desember 2010. Diambil dari: http://ilib.ugm.ac.id/jurnal/detail.php?datald=12023

Sukahridhoto, Sriturusta (2014). Buku Jaringan Komputer 1. Diambil dari: http//dhoto.lecture.pens.ac.id/publications/boo k/2014/ (3 Desember 2016).

Sumarno, Eko dan Hasmoro H.P ( 2013). Implementasi Metode Load Balancing Dengan Dua Jalur. ISSN: 2302-5700. Karanganyar: Indonesian Jurnal on Networking and Security Vol. 2, No 1 Juli 2013. Diambil dari: http://ijns.org/journal/index.php/ijns/article/view 147

Supriyanto, Kadek (2014). Jaringan Komputer I. Diambil dari: http//bse.kemndikbud.go.id/index.php/buku/rea d/921580ee-4432-4fda-a020-7ace364a2611 (12 Desember 2016).

Towidjojo, Rendra. (2016). Mikrotik Kungfu Kitab 2. Jakarta: Jasakom. 